\title{
Prophylactic Use of the New Quinolones for Prevention of Nosocomial Infection in the Intensive Care Unit
}

\author{
Peter D. Potgieter ${ }^{1}$ and Janet M.J. Hammond ${ }^{2}$ \\ 1 Respiratory Intensive Care Unit, Departments of Anaesthesia and Medicine, University of Cape Town and \\ Groote Schuur Hospital, Observatory, South Africa \\ 2 Department of Infectious Diseases, Duke University, Durham, North Carolina, USA
}

\section{Summary}

The use of prophylactic antibacterials, especially when required for a prolonged period, always causes concern regarding the induction of resistance. This particularly applies in the intensive
The new quinolone antimicrobial agents, particularly those with less activity against anaerobes, selectively prevent colonisation of the alimentary tract by Gram-negative bacilli and staphylococci without substantially affecting the normal anaerobic flora, which preserve the colonisation resistance of the gut. These properties ideally position this class of antibacterial agent for selective decontamination of the digestive tract (SDD) in the prevention of nosocomial infection. The rationale for this procedure is based on the presumption that a significant proportion of infections in compromised patients are endogenous in origin, arising from the host's own microbial flora. If this colonisation by potentially pathogenic microflora within the normal flora can be significantly reduced without being replaced by other more pathogenic microorganisms, the risk of endogenous infection should be minimised.

The quinolones have proved to be ideal agents for use in preventing infection in bone marrow transplant and other neutropenic patients. They have been used for SDD in the general intensive care unit population, although the technique has not received widespread acceptance. There have been only 4 reported randomised studies using quinolones as part of SDD regimens and only 301 patients have been evaluated. Although the incidence of ventilator-associated pneumonia has been significantly reduced from 36 to $15 \%$, no effect has been shown on mortality. The cost of using SDD is significantly less with the quinolones than with other regimens, and induction of resistance has not been noted.

The new quinolones, and in particular the more recently developed agents with extended Gram-positive activity, appear to be ideally suited for SDD, and their careful evaluation in further large, well designed trials is warranted. 
Klick et al., ${ }^{[1]}$ who used aerosolised endotracheal polymixin in ventilated patients. Their promising initial results showed that the incidence of nosocomial pneumonia was reduced from 40 to $10 \%$; however, within a year, a second paper by the same group reported problems with infections caused by polymixin-resistant organisms and other unusual pathogens, with a higher patient mortality than previously, and it was concluded that this was a 'dangerous' practice. ${ }^{[2]}$

With the increasing complexity of the diseases being treated in the ICU and more aggressive therapy being used for patients with haematological malignancies, nosocomial infections have become increasingly prevalent and significantly contribute to mortality. While exogenous infections could be largely controlled by handwashing and aseptic techniques, it became apparent that most of these infections were endogenous rather than exogenous in origin, and thus would lend themselves to being controlled by prophylactic antibacterial therapy. ${ }^{[3,4]}$ This led to early attempts at total decontamination, with complete control of the environment, including the use of laminar flow nursing rooms as well as sterile foods in bone marrow transplant patients, with some initial success. ${ }^{[5]}$ It soon became obvious, however, that the 'normal' host flora played an important role in preventing colonisation by other, more pathogenic, microorganisms; thus, the antibacterial regimens were modified, with the aim of leaving this largely anaerobic flora intact. ${ }^{[6]}$ Antibacterials such as polymixin, cotrimoxazole (trimethoprim-sulfamethoxazole) and the new quinolones, which exert their main activity against the aerobic Gram-negative microorganisms and therefore have minimal effect on this 'colonisation resistance' flora, have all proved useful in this setting. The use of these drugs is termed selective decontamination (SD). ${ }^{[7]}$

The success of SD in this group of patients soon led to its introduction in the ICU, where the technique is known as selective decontamination of the digestive tract (SDD) and has received wide acceptance. Nevertheless, there is controversy surrounding its lack of effect on mortality, although it de- creases the incidence of ventilator-associated pneumonia. ${ }^{[8]}$

\section{Rationale for SDD}

In ICUs where exogenous infection has largely been eliminated by usual infection control measures, the incidence of nosocomial infection is 15 to $50 \%$, depending on the population. This infection is usually of direct endogenous origin, although the microorganisms are frequently acquired in hospital and are not necessarily the patient's own normal flora. These microorganisms first colonise the alimentary tract and, in intubated patients, this subsequently leads to bronchial acquisition and colonisation, often within 24 to 48 hours of admission. Given time, a large inoculum of pathogenic microbes and depressed humoral defences, this colonisation will frequently lead first to bronchial infection and then spread to the lung parenchyma. ${ }^{[4,9,10]}$ While normal nursing procedures such as mouth and endotracheal tube and cuff care combined with limited sedation, gastric acid maintenance and mobilisation with physiotherapy will help to prevent the onset of pneumonia, elimination of Gram-negative and other highly pathogenic colonisers of the alimentary tract should go a long way towards providing complete protection. ${ }^{[11,12]}$

\section{Antibacterial Regimens in SDD}

The properties of the antimicrobial agents used for SDD are of vital importance for the success of this technique. Ideally, they should eliminate the potentially pathogenic microorganisms from the alimentary tract without influencing the largely anaerobic normal flora, which provide colonisation resistance against other microorganisms that may be unaffected by the SDD regimen and more dangerous than the original microorganisms. In addition, the SDD regimen should not induce resistance, as it is often required for a prolonged period and infections with resistant organisms may then develop.

The quinolones, particularly norfloxacin, have been widely used for SD in patients with 
Table I. Influence of orally administered norfloxacin on intestinal microflora in healthy volunteers ${ }^{[16-18]}$ and patients being treated for urinary tract infections ${ }^{[19]}$

\begin{tabular}{|c|c|c|c|c|c|c|c|c|}
\hline \multirow{2}{*}{$\begin{array}{l}\text { Reference } \\
\text { no. }\end{array}$} & \multirow{2}{*}{$\begin{array}{l}\text { No. of } \\
\text { volunteers/ } \\
\text { patients }\end{array}$} & \multirow{2}{*}{$\begin{array}{l}\text { Dose } \\
\text { (mg/day) }\end{array}$} & \multirow{2}{*}{$\begin{array}{l}\text { Test } \\
\text { day }^{a}\end{array}$} & \multicolumn{2}{|c|}{$\begin{array}{l}\text { Norfloxacin } \\
\text { concentrations }\end{array}$} & \multicolumn{3}{|c|}{ Effects on faecal microorganisms } \\
\hline & & & & $\begin{array}{l}\text { serum } \\
\text { (peak, mg/L) }\end{array}$ & $\begin{array}{l}\text { faeces } \\
(\mathrm{mg} / \mathrm{kg})\end{array}$ & Enterobacteriaceae & enterococci & anaerobes \\
\hline$\overline{18}$ & 10 & $200 \times 2$ & 7 & $0.75 \pm 0.15$ & $303-1906$ & $+1+$ & NC & $\mathrm{NC}$ \\
\hline 16 & 10 & $400 \times 2$ & 8 & $1.58 \pm 0.37$ & & $+H$ & NC & NC \\
\hline 17 & 6 & $200 \times 2$ & 5 & $1.0 \pm 0.3$ & $2271 \pm 859$ & $+1+$ & NC & NC \\
\hline 17 & 6 & $400 \times 2$ & 6 & $1.9 \pm 0.9$ & & $+H$ & + & NC \\
\hline 19 & 8 & $400 \times 2$ & 90 & ND & 1756 & $H+$ & + & NC \\
\hline
\end{tabular}

a Duration of administration of norfloxacin prior to microbiological sampling.

Abbreviations and symbols: $\mathrm{CFU}=$ colony-forming units; $\mathrm{NC}=$ no significant change; $\mathrm{ND}=$ not done; $++=$ very strong suppression $(>4$ log 10 CFU/g faeces); + = mild suppression ( $2 \log _{10}$ CFU/g faeces).

Table II. Spectrum of in vitro activity of ofloxacin, ciprofloxacin and sparfloxacin

\begin{tabular}{llll}
\hline Organism & $\mathrm{MIC}_{90}(\mathrm{mg} / \mathrm{L})$ & & ofloxacin \\
\cline { 2 - 4 } & sparfloxacin & ciprofloxacin & $2-8$ \\
\hline Streptococcus pneumoniae & $0.25-1$ & $0.5-4$ & $0.5-1$ \\
Staphylococcus aureus & $0.06-0.25$ & $0.25-2$ & $2-4$ \\
Enterococcus faecalis & $0.5-2$ & $1-4$ & 6.25 \\
E. faecium & $0.39-1$ & $2-4$ & $0.25-1$ \\
Klebsiella pneumoniae & $0.06-0.5$ & $0.03-1$ & $0.12-1.56$ \\
Proteus spp. & $0.25-1$ & $0.01-0.5$ & $4-16$ \\
Acinetobacter spp. & $0.01-0.12$ & $0.12-1$ & $8-12.5$ \\
Pseudomonas aeruginosa & $1-8$ & $0.25-4$ & 8 \\
Bacteroides fragilis & $1-2$ & $4-32$ & 16 \\
Prevotella spp. & $8-16$ & & \\
\hline
\end{tabular}

haematological disease and all have been shown to be effective. They have ideal properties in terms of their spectrum of activity, which covers most Gram-negative microorganisms and leaves the Gram-positive microorganisms, particularly the anaerobes, untouched. ${ }^{[13,14]}$ Numerous studies have evaluated these effects, as well as antibacterial concentrations in the faeces, and these results are summarised in table I. ${ }^{[7,15-17]}$ Interestingly, at higher doses there may be a greater effect on problematic organisms such as the enterococci and it may be possible to use this property to good effect with SDD regimens. ${ }^{[14,17]}$ The newer agents (such as sparfloxacin) with better Gram-positive coverage may have a role in this area, but this extended spectrum of activity usually includes the anaerobes (table II).
The quinolones have the additional advantage of being much cheaper than other regimens used for SDD and, in addition, they provide the systemic effect needed for rapid action. They are also much more easily administered than the standard topical oropharyngeal paste and enteral regimens. The most commonly used regimen popularised by Van Saene and Stoutenbeek consists of tobramycin, polymixin $\mathrm{E}$ and amphotericin $\mathrm{B}$, which is given both enterally by nasogastric tube and by oropharyngeal paste every 6 hours, with intravenous cefotaxime every 8 hours for the first 5 days. ${ }^{[20]}$ This regimen also provides very specific cover against Gram-negative and yeast species, and numerous studies have demonstrated the efficiency with which it decontaminates the alimentary tract. Although there has been concern about the develop- 
ment of resistance to the agents used, this has been demonstrated in only a small number of studies: in one, increasing resistance to tobramycin occurred among Staphylococcus aureus isolates and, in another, an increasing number of isolates of Acinetobacter spp. was found. ${ }^{[21,22]}$ As these potent agents are not absorbed they can be used in dosages far exceeding the minimum inhibitory concentrations of resistant microorganisms, and cover against Proteus and Morganella spp. is provided by the tobramycin. However, some investigators have reported increasing colonisation by staphylococci and enterococci, which has not resulted in infection but is of concern. ${ }^{[23,24]}$

Cotrimoxazole has been used either alone (mostly in patients with haematological disease), or as part of SDD regimens, where it has been shown to be effective. ${ }^{[25]}$ It has the additional advantage of providing systemic effects, as well as prophylaxis against Pneumocystis carinii, but is most likely to lead to resistance if used alone. [7]

Vancomycin has also been combined in a regimen with polymixin $\mathrm{E}$ and amphotericin $\mathrm{B}$, effectively broadening the cover against staphylococci and enterococci. ${ }^{[26]}$ The influence of this regimen on the anaerobic flora may well limit colonisation resistance; however, the effect of this has not been adequately explored.

Thus, it would appear that there is no ideal agent or combination of agents for SDD at present; any new agent that has largely Gram-negative cover with some activity against staphylococci and en- terococci and minimal effect on the anaerobes should be considered for use in this setting.

\section{Efficacy of SDD}

The efficacy of SDD is possibly one of the most contentious areas in critical care at present; despite more than 3 major meta-analyses of data from over 3000 randomised patients no consensus exists, and its role is still debatable. ${ }^{[8,27,28]}$ There is some agreement on its effect in decreasing the incidence of lower respiratory tract infections. It would appear that between 5 and 9 (mean 6) patients need to be treated to prevent one respiratory infection, and the higher the background incidence of infection, the easier it is to show a positive effect of SDD. The influence on mortality is inexplicably less clear, and it would seem that 13 to 139 (mean 23) patients need to be treated to prevent one death. ${ }^{[8]}$ A criticism of these meta-analyses is that there are many discrepancies in diagnostic and other clinical criteria between the reported studies, most of which are poorly designed. Perhaps one of the most important factors is that the various antibacterial regimens may differ significantly in efficacy, but this is not taken into account.

\section{Role of Quinolones in SDD}

The quinolones have firmly established their place in SD in severely immunocompromised patients with haematological disease, from the perspective of both efficacy in reducing mortality and of the cost of the regimen. Unfortunately, their role

Table III. Results of clinical trials of selective decontamination of the digestive tract (SDD) using quinolones in the decontamination regimen

\begin{tabular}{|c|c|c|c|c|c|c|c|}
\hline \multirow[t]{2}{*}{ Study population } & \multirow{2}{*}{$\begin{array}{l}\text { No. of patients } \\
\text { (SDD/control) }\end{array}$} & \multirow[t]{2}{*}{ SDD regimen } & \multirow{2}{*}{$\begin{array}{l}\text { Methodology } \\
\text { score }^{\text {a }}\end{array}$} & \multicolumn{2}{|c|}{ Rate of infection (\%) } & \multicolumn{2}{|c|}{ Mortality (\%) } \\
\hline & & & & SDD & control & $\overline{S D D}$ & control \\
\hline $\mathrm{T}, \mathrm{S}, \mathrm{M}^{[29]}$ & $28 / 60$ & $\begin{array}{l}\text { P, NOR, } \\
\text { AMB, C }\end{array}$ & 12 & 4 & 48 & 14 & 20 \\
\hline $\mathrm{T}, \mathrm{S}, \mathrm{M}^{[30]}$ & $193 / 185$ & OFL, AMB & 11 & 11 & 22 & 24 & 22 \\
\hline $\mathrm{T}, \mathrm{S}, \mathrm{M}^{[31]}$ & $55 / 57$ & $\begin{array}{l}\text { P, NOR, } \\
\text { AMB }\end{array}$ & 12 & 13 & 46 & 40 & 58 \\
\hline $\mathrm{S}^{[32]}$ & $25 / 23$ & NOR, NY & 15 & 56 & 100 & 52 & 43 \\
\hline Total & $301 / 325$ & & 12.5 & 15 & 36 & 29 & 29 \\
\hline
\end{tabular}

a Heyland et al.[28]

Abbreviations: $\mathrm{AMB}=$ amphotericin $\mathrm{B} ; \mathrm{C}=$ cefotaxime; $\mathrm{M}=$ medical; $\mathrm{NOR}=$ norfloxacin; $\mathrm{NY}=$ nystatin; $\mathrm{OFL}=$ ofloxacin; $\mathrm{P}=$ polymixin $\mathrm{E}$; $\mathrm{S}=$ surgical; $\mathrm{T}=$ trauma. 
in the ICU has been inadequately investigated and only 4 controlled studies have been reported. [29-32] These studies, which were of adequate scientific standard as described by Heyland et al., ${ }^{[28]}$ reported on the use of quinolones, usually as part of multiple drug regimens. All 4 studies (3 with norfloxacin and 1 with ofloxacin) demonstrated a significant reduction in the incidence of infection that was possibly greater than that of the other regimens (table III). Increased antibacterial resistance was not detected. As in previous studies, the effects on mortality were equivocal. In a further noncomparative study using norfloxacin, sulfamethoxypyrazine, and amphotericin B over three 6-month periods, the incidence of infection was reduced from 75 to $30 \%$. This was largely related to a decrease in respiratory infections and septicaemia caused by Enterobacteriaceae and Pseudomonas spp. Again, no effect on mortality was observed over the period of SD. ${ }^{[33]}$

The major difference between SD for patients with haematological disease and SDD in the ICU is that the patients in the ICU frequently require prophylaxis for a much longer period. The effectiveness of a quinolone regimen in this area may therefore be limited by the potential of these agents to induce antimicrobial resistance after prolonged use. A recent study examining the risk factors in 68 patients who had developed infection with quinoloneresistant microorganisms found that prior quinolone therapy was an independent risk factor. ${ }^{[34]}$ When norfloxacin was used prophylactically in a group of 31 hospitalised alcoholic cirrhotic patients in an attempt to decrease the risk of spontaneous bacterial peritonitis, no selection of resistant organisms occurred in 15 patients; however, in the remaining 16 , resistant faecal organisms were detected from the second week of treatment. These included $S$. aureus (4), coagulase-negative staphylococci (6), Citrobacter freundii (4), Enterobacter spp. (3), Klebsiella oxytoca (2), Providencia rettgeri (1) and untypeable streptococci (6). ${ }^{[33]}$ Other studies have suggested that ciprofloxacin may in fact increase the incidence of candidal colonisation and infection. ${ }^{[14]}$

\section{Conclusions}

The quinolone antibacterials, including norfloxacin, ofloxacin, ciprofloxacin and pefloxacin, are all useful agents for SD in severely compromised agranulocytopenic patients. Their use in SDD in ICU patients has been inadequately investigated, and although these 'older' new quinolones show much promise in this area the newer agents with enhanced Gram-positive cover may be even better, provided that they have only a minimal effect on colonisation resistance. These agents warrant further evaluation in large, well designed trials.

\section{References}

1. Klick JM, Du Moulin GC, Hedley-Whyte J, et al. Prevention of Gram negative bacillary pneumonia using polymyxin aerosol as prophylaxis. J Clin Invest 1975 ; 55: 514-9

2. Feeley TW, Du Moulin GC, Hedley-Whyte J, et al. Aerosol polymyxin and pneumonia in seriously ill patients. N Engl J Med 1975; 293: 471-5

3. Schwartz SN, Dowling JN, Benkovic C. Sources of Gram negative bacilli colonising the tracheae of intubated patients. J Infect Dis 1978; 138: 227-31

4. Neu HC. Colonisation resistance: fact or fancy, significant or insignificant? Eur J Clin Microbiol Infect Dis 1988; 7: 91-2

5. Buckner CD. Protective environment for marrow transplant recipients. A prospective study. Ann Intern Med 1978; 89: 893901

6. Guiot HFL, Van der Meer JWM, Van Furth R. Selective antimicrobial modulation of human microbial flora: infection prevention in patients with decreased host defense mechanisms by selective elimination of potentially pathogenic bacteria. $\mathbf{J}$ Infect Dis 1981; 143: 644-54

7. Guiot HFL, Van Furth R. Selective decontamination in bone marrow transplant recipients. Epidemiol Infect 1992; 109: $349-60$

8. Selective Decontamination of the Digestive Tract Trialists' Collaborative Group. Meta-analysis of randomised controlled trials of selective decontamination of the digestive tract. BMJ 1993; 307: 525-32

9. Niederman MS, Mantovani R, Schoch P, et al. Patterns and routes of tracheobronchial colonisation in mechanically ventilated patients: the role of the nutritional status in colonisation of the lower airway by Pseudomonas species. Chest 1989; 95: 155-61

10. A'Court C, Garrard CS. Nosocomial pneumonia in the intensive care unit: mechanisms and significance. Thorax 1992; 47: 465-73

11. Craven DE, Steger KA, Barber TW. Preventing nosocomial pneumonia: state of the art and perspectives for the 1990s. Am J Med 1991; 91: 44-53S

12. Weinstein RA. Epidemiology and control of nosocomial infections in adult intensive care units. Am J Med 1991; 91: 179$84 \mathrm{~S}$

13. van der Waaij D, Manson WL, Arends JP, et al. Clinical use of selective decontamination: the concept. Intensive Care Med 1990; 16: S3, S212-15 
14. Edlund C, Nord CE. Suppression of the oropharyngeal and gastrointestinal microflora by ciprofloxacin: microbiological and clinical consequences. Scand J Infect Dis Suppl. 1989; 60: $98-103$

15. Edlund C, Nord CE. Manipulation of the oropharyngeal and intestinal microflora by norfloxacin: microbiological and clinical aspects. Scand J Infect Dis Suppl. 1988; 56: 14-21

16. Leigh DA, Emmanuel FXS, Tighe C, et al. Pharmacokinetic studies of norfloxacin chemotherapy in healthy volunteers and effect on the faecal flora [section 2]. Recent advances in chemotherapy. Proceedings of the 14th International Congress of Chemotherapy; 1985; Istanbul: 1835-6

17. Pecquet S, Andremont A, Tancrede C. Selective antimicrobial modulation of the intestinal tract by norfloxacin in human volunteers and in gnotobiotic mice associated with a human faecal flora. Antimicrob Agents Chemother 1986; 29: $1047-$ 52

18. Edlund C, Bergan T, Josefsson K, et al. Effect of norfloxacin on human oropharyngeal and colonic microflora and multiple dose pharmacokinetics. Scand J Infect Dis 1987; 19: 113-21

19. Boerema JBJ, Olthof BJ, Van Saene HKF. Effects of norfloxacin on the faecal flora in patients with complicated urinary tract infections. Scand J Infect Dis 1986; Suppl. 48: 27-31

20. Stoutenbeek CP, Van Saene HKF, Miranda DR, et al. A new technique of infection prevention in the intensive care unit by selective decontamination of the digestive tract. Acta Anaesthesiol Belg 1983; 3: 209-21

21. Nau R, Ruchel R, Mergerian H, et al. Emergence of antibiotic resistant bacteria during selective decontamination of the digestive tract. J Antimicrob Chemother 1990; 25: 881-3

22. Winter R, Humphreys H, Pick A, et al. A controlled trial of selective decontamination of the digestive tract in intensive care and its effect on nosocomial infection. J Antimicrob Chemother 1992; 30: 73-87

23. Konrad F, Schwalbe B, Heiderich P, et al. Bacterial colonisation and respiratory tract infections in long term ventilated patients under conventional antibiotic treatment and selective decontamination of the digestive tract (SDD) [abstract]. Intensive Care Med 1988; 14

24. Hammond JMJ, Potgieter PD, Saunders GL, et al. Double-blind study of selective decontamination of the digestive tract in intensive care. Lancet 1992; 340: 5-9
25. Dekker AW, Rosenberg-Arska M, Sixma JJ, et al. Prevention of infection by trimethoprim-sulphamethoxazole plus amphotericin B in patients with non-lymphocytic leukaemia. Ann Intern Med 1991; 95: 555-9

26. Pugin J, Auckenthaler R, Lew DP, et al. Oropharyngeal decontamination decreases incidence of ventilator associated pneumonia: a randomised, placebo controlled double blind clinical trial. JAMA 1991; 265: 2704-10

27. Vandenbroucke-Grauls CMJE, Vandenbroucke JP. Effect of selective decontamination of the digestive tract on respiratory tract infections and mortality in the intensive care unit. Lancet 1991; 338: 859-62

28. Heyland DK, Cook DJ, Jaeschke R, et al. Selective decontamination of the digestive tract. An overview. Chest 1994; 105: 1221-5

29. Aerdts SJ, Clasener HA, van Dalen R, et al. Prevention of bacterial colonisation of the respiratory tract and stomach of mechanically ventilated patients by a novel regimen of selective decontamination in combination with initial systemic cefotaxime. J Antimicrob Chemother 1990; 26 Suppl. A: 59-76

30. Verhaegen J. Randomised Study of selective digestive decontamination on colonisation and prevention of infections in mechanically ventilated patients in the ICU [thesis]. University of Louvain, Belgium, 1993

31. Ulrich C, Harinck-de Weerd JE, Bakker NC, et al. Selective decontamination of the digestive tract with norfloxacin in the prevention of ICU acquired infections: a prospective randomized study. Intensive Care Med 1989; 15: 424-31

32. Cerra FB, Maddaus MA, Dunn DL, et al. Selective gut decontamination reduces nosocomial infections and length of stay but not mortality or organ failure in surgical intensive care unit patients. Arch Surg 1992; 127: 163-9

33. van Griethuysen AJA, Clasener HAL, Vollard EJ, et al. Colonization resistance: a guide to antibiotic policy in the ICU. Infect Contr 1987; 8: 269-70

34. Richard P, Delangle M, Merrien D, et al. Fluoroquinolone use and fluroquinolone resistance: is there an association? Clin Infect Dis 1994; 19: 54-9

Correspondence and reprints: Dr Peter D. Potgieter, Respiratory Intensive Care Unit, Groote Schuur Hospital, Observatory, 7925, South Africa. 